\title{
Transdisciplinariedad en la universidad: Experiencias en el Centro de Estudios Universitarios Arkos, México.
}

\author{
Ana Cecilia Espinosa Martínez * \\ Pascal Galvani **
}

\begin{abstract}
Resumen
El texto explica algunas de las experiencias de CEUArkos para poner en práctica la transdisciplinariedad en la universidad, así como los procesos de duración y el aprendizaje logrado con tanta experiencia a lo largo de 5 estrategias universitarias para una educación transdisciplinar y compleja. Se exllanuras de la experiencia transdisciplinar de una universidad concreta a escala global de una institución: CEUArkos, que desde 2006 ha estado explorando y experimentando con los miembros de su comunidad (profesores, estudiantes, directores) las formas de orientar el proceso de ir en el universidad de una educación disciplinaria a un transdisciplinar uno en todos sus programas educativos.

Palabras clave: La Transdisciplinariedad. Complejidad. Eco-Formación. Investigación-Acción.

Transdisciplinary University: Experiences Arkos Center University Studies, Mexico
\end{abstract}

\begin{abstract}
The text explains some of the experiences of CEUArkos to implement transdisciplinarity in the university as well as the lived processes and the learning achieved with such experience throughout 5 big university strategies for a transdisciplinar and complex education. It explains the transdisciplinar experience of a concrete university at a global scale of an institution: CEUArkos, which since 2006 has been exploring and experimenting with the members of its community (teachers, students, directors) the ways to orient the process of going in the university from a disciplinary education to a transdisciplinar one in all its educational programs.

Key words: Transdisciplinarity, Complexity, Eco-formacion, Research-Action.
\end{abstract}

En las siguientes líneas compartimos con usted, amable lector, los procesos de investigación-acción-formación (y por tanto de auto-eco-reorganización) desarrollados en el Centro de Estudios Universitarios Arkos ${ }^{1}$ (CEUArkos), de Puerto Vallarta,

\footnotetext{
* Diretora Acadêmica do Centro de Estudios Universtarios Arkos (México). E-mail: ceci_vallarta@hotmail.com

** Doutor em Ciências da Educação pela Universidade François Rabelais (Tours/França). Professor da Universidade do Quebéc (Canadá).E-mail: pascal_galvani@uqar.qc.ca

1 El CEUArkos, retoma como parte de su identidad uno de los iconos de la ciudad de Puerto Vallarta, los
} 
Jalisco, México, para institucionalizar la transdisciplinariedad y la complejidad como parte de las prácticas formativas universitarias así como del currículo, avalado por la Secretaría de Educación Pública del país. Para ello, planteamos dos grandes apartados que sintetizan a la vez que los trabajos para operacionalizar la transdisciplinariedad, dos publicaciones ${ }^{2}$ (Espinosa y Galvani 2014; Espinosa, 2014) que aglutinan la experiencia desarrollada por los actores universitarios para transitar en sus prácticas de la disciplinariedad a la transdisciplinariedad en la enseñanza, el aprendizaje y la investigación en la institución citada, creando estrategias concretas de acción.

La experiencia se asienta epistemológicamente y teóricamente en la transdisciplinariedad y la complejidad; pero emerge a partir de una problemática vivida por los actores universitarios del CEUArkos quienes advirtieron una fractura entre su práctica universitaria y la filosofía institucional con la que se sienten identificados -filosofía que postula una formación integral de la persona-. Hablamos, pues, de una experiencia teórico-práctica que asume las características de una investigación-acción (I-A) e incorpora la reflexión y la colaboración de los participantes en todo momento de su realización.

La investigación asume pues como postura epistemológica aquella denominada por Nicolescu (1998) como transdisciplinar (a menudo relacionada y confundida con los términos multidisciplinariedad e interdisciplinariedad ${ }^{3}$, a los que trasciende)

arcos del malecón. La palabra arkos proviene de arkhé. En la filosofía griega, los pensadores presocráticos comenzaban preguntándose por el arkhé de las cosas, el principio supremo unificador de los fenómenos y que está en la base de todas las transformaciones. La "k" se incorpora así, en el nombre de la institución, inspirada en ese significado y también en el vocablo griego kinesis, que significa movimiento o dinámica, en este caso la dinámica de transformación que la institución debe generar en su relación dialéctica y dialógica con la comunidad que la vio nacer, por ello, las arcadas simbolizan la unión e identificación entre la ciudadanía y el centro universitario.E-mail: pascal_galvani@uqar.ca

2 Los textos referidos son: a) Espinosa Martínez, Ana Cecilia y Pascal Galvani (2014) "Transdisciplinariedad y formación universitaria: Teorías y prácticas emergentes” CEUArkos. México. b) Espinosa Martínez, Ana Cecilia (2014) "Abrir los saberes a la complejidad de la vida: Nuevas prácticas universitarias en la universidad."

3 Las disciplinas son cuerpos de conocimiento científico, plausibles de organizarse sistemáticamente para ser enseñados, que se encargan del estudio de fragmentos específicos de la realidad -dichos fragmentos constituyen el dominio material u objeto de la disciplina- y de la búsqueda continua de conocimientos nuevos que desplazan a los antiguos, sobre la materia particular de que se ocupan." (Espinosa y Tamariz, 2006). "La pluridisciplinariedad consiste en el estudio del objeto de una sola y misma disciplina por medio de varias disciplinas a la vez. El objeto saldrá así enriquecido por la convergencia de varias disciplinas. El conocimiento del objeto dentro de su propia disciplina se profundiza con la aportación pluridisciplinaria fecunda" (Nicolescu, 1998, p.2). Se trata, pues, de un conjunto de disciplinas que abordan diversos aspectos o ámbitos de un mismo problema, sin que las disciplinas que contribuyen sean cambiadas o enriquecidas. De modo que la relación pluridisciplinar no ofrece posibilidades de relación en sentido estricto, sólo permite la convergencia entre las ciencias afectadas. Según Piaget la 
y por Morin (2005, 2006, 2006b, 2006c, 2006d, 2006e, 2006f) como compleja. De allí que de acuerdo con Moraes (2005), quien hace una propuesta de tipificación de los paradigmas epistemológicos en: positivista, interpretativo, sociocrítico y paradigma eco-sistémico complejo, nos ubiquemos en este último.

El paradigma eco-sistémico complejo, tiene una base: “...constructivista, interaccionista, intersubjetiva y dialógica, (asume la reintroducción del sujeto cognoscente en todo conocimiento), acepta la naturaleza múltiple y diversa del sujeto y del objeto estudiado, envolviendo una dinámica no lineal, dialógica, interactiva, recursiva y abierta; que rescata la bio-psico-génesis del conocimiento humano; y asume que sujeto y objeto son ecológicamente indisociables e interdependientes. (Moraes, 2008, p. 16-17) ${ }^{4}$

Para autoras como Thompson Klein, 2013, esta postura se ubica dentro de lo que ella titula una perspectiva transdisciplinar que pasa de la noción de unidad a la noción de complejidad.

\section{Transdisciplinariedad y formación universitaria: teorías y prácticas emergentes.}

\subsection{Contextualización de la experiencia}

Podemos decir que desde el siglo XIX la educación y, en particular la educación superior, en su mayor parte, se ha distinguido por su carácter disciplinario, por organizar e impartir el conocimiento en forma fragmentada, agrupando el saber dentro de los currículos en unidades aisladas, sin relación unas con otras, como piezas sueltas de un rompecabezas que se le entregan al alumno sin proporcionarle las instrucciones para armarlo. Este fenómeno no es gratuito, se trata del reflejo en el terreno educativo, de la forma en que se organiza y produce el conocimiento científico, cuyos resultados conforman los contenidos de la educación en el mundo moderno: la disciplinariedad, que tiende a la atomización del saber y se sustenta en el paradigma positivista clásico de la ciencia.

interdisciplinariedad se da "donde la cooperación entre varias disciplinas o sectores heterogéneos de una misma ciencia llevan a interacciones reales, es decir, hacia una cierta reciprocidad de intercambios que dan como resultado un enriquecimiento mutuo" (Piaget, 1979, p. 67).

4 Como parte de la dimensión ontológica del paradigma, Moraes (2008, p. 16-17) contempla, y con ella estamos de acuerdo, que "la realidad es una unidad global, compleja, integrada; es dinámica, relacional, indeterminada y no lineal, en ella aparecen los contrarios a la vez que como antagónicos, complementarios; es construida por la relación sujeto/objeto; es multidimensional; existen diferentes niveles de realidad; la complejidad es constitutiva de la realidad, del pensamiento y la acción." 
La universidad donde se contextualiza nuestro objeto de estudio no es la excepción. El CEUArkos está ubicado en la ciudad de Puerto Vallarta, Jalisco en México, es una Institución de Educación Superior (IES) inscrita en esta problemática dominante de una educación fragmentaria, en la que sus funciones sustantivas y programas de educación se organizan bajo la perspectiva disciplinaria. Se trata de una institución de carácter privado, con reconocimiento de validez oficial de la Secretaría de Educación Pública (SEP), fundada en 1990 por educadores con muchos años de experiencia en la formación de jóvenes y adultos en el ámbito de la educación pública, popular. Fue la primera universidad que existió en la región. Oferta carreras de nivel licenciatura bajo el modelo presencial en las áreas de: Derecho, Contaduría, Ciencias de la Comunicación, Administración de Empresas Turísticas y Mercadotecnia. Es una universidad pequeña, con una población estudiantil que oscila entre los 300 y 400 estudiantes y cuenta con una planta docente promedio de 50 profesores-profesionales en diversas áreas del conocimiento que se caracterizan, además de tener una formación académica, por estar involucrados no sólo en la docencia sino en el ejercicio continuo de la profesión. El perfil de los estudiantes es particular, el 70\% de ellos trabaja, por esta razón los cursos se dan en la tarde de las 17:00 a las 22:00 horas y los sábados de las 8:00 a las 14:00 horas.

No obstante que la práctica educativa del CEUArkos es disciplinaria, su filosofía institucional posee una orientación humanista sintetizada en su lema "Educar es formar hombres libres". La universidad tiene dentro de sus ideales una formación integral del individuo. Animada por esa visión humanista de la educación, la dirección del centro se interesó muy temprano por la aproximación transdisciplinar. La visión crítica de la comunidad universitaria y el sentido de comunidad de aprendizaje que existe en ella, permitió advertir a sus miembros una brecha entre la filosofía institucional y la forma en que eran conducidas sus licenciaturas por lo que en sus planes estratégicos (2003-2008) buscaron crear medios que permitieran reducir esta brecha y alcanzar el ideal de una formación más integral, pero el problema era que carecían de las estrategias que les permitieran hacerlo.

De allí que la pregunta central de la pesquisa fuera: ¿Cómo operacionalizar, metodológicamente, en conjunto con los actores universitarios, la práctica educativa transdisciplinaria -en las tareas del aprendizaje, la enseñanza y la investigación como parte de la docencia- en las licenciaturas del CEUArkos de Puerto Vallarta, Jalisco, México? y que el objetivo general de la investigación fuese develar las formas de llevar a cabo la práctica educativa transdisciplinaria, de la mano de los actores universitarios en las licenciaturas de la institución. 
1.2 La triada básica para una nueva formación universitaria: Transdisciplinariedad, complejidad y eco-formación.

Como señalamos, el fundamento teórico de la pesquisa se asentó en la transdisciplinariedad y la complejidad y sus derivaciones en la educación de nivel superior. La transdisciplinariedad y la complejidad representan dos formas de pensamiento de actualidad que se suman a la búsqueda de una perspectiva integradora del conocimiento y la realidad en reacción a una visión atomizante y fragmentadora de la misma. Quizá, es más adecuado decir que éstas representan dos formas de llamar al nuevo paradigma de la ciencia. Los teóricos más importantes son Nicolescu y Morin. La relación entre ambas teorías es insoslayable, pues la transdisciplinariedad concibe como uno de sus principios rectores a la complejidad. A estas visiones se aúna la perspectiva eco-formadora que retoma el vínculo: individuo ßàsociedadßànaturaleza, el triángulo de la vida (D’Ambrosio, 2007), tripolaridad que estructura las investigaciones sobre la formación humana (Pineau, 2007). Por razones de espacio, no profundizaremos en cuestiones conceptuales sobre estas perspectivas, sólo las enmarcaremos en el contexto de la pesquisa que realizamos, empero adelantamos que ellas sintetizan lo que podríamos llamar la triada básica para una nueva formación universitaria.

\subsubsection{La Transdisciplinariedad}

La transdisciplinariedad es entendida, según Nicolescu (1998), como aquello que está al mismo tiempo entre las disciplinas, a través de las diferentes disciplinas y más allá de cualquier disciplina. Nace para atender la necesidad de lidiar con los desafíos sin precedentes del mundo problematizado en que vivimos y que requieren de un tratamiento multi-referencial dado que son complejos. Su finalidad es la comprensión del mundo y la articulación de las diferentes áreas del conocimiento y los saberes. Se apoya en los pilares de la complejidad, los niveles de realidad y la lógica del tercero incluido, los cuales definen su metodología y nueva visión de la naturaleza y el ser humano (Nicolescu, 2006).

\subsubsection{La Complejidad}

La complejidad (lo que está tejido entre), es una perspectiva animada por una tensión permanente entre la aspiración a un saber no parcelado, no dividido, no reduccionista y el reconocimiento de lo inacabado e incompleto de todo conocimiento. Para esta corriente, la realidad es compleja, implica a la vez lo uno y lo múltiple, es unitas multiplex (Morin, 2001). Para abordar los problemas que arroja la realidad, la 
complejidad propone una revolución del pensamiento que permita el advenimiento de un pensamiento complejo, capaz de asociar lo que está desunido y concebir la multidimensionalidad de toda realidad antroposocial mediante la aplicación de siete principios: sistémico u organizacional, hologramático, retroactividad, recursividad, autonomía/dependencia, dialógico, reintroducción del sujeto en todo conocimiento (Morin 2005).

\subsubsection{La eco-formación}

La eco-formación es, desde la perspectiva de los participantes del Congreso de Transdisciplinariedad de Barcelona (2007), la acción educativa ecologizada, es decir, enraizada en la dinámica relacional entre el ser humano, la sociedad y la naturaleza de manera que resulte sustentable en el espacio y el tiempo. Retoma el triángulo de la vida (D’Ambrosio, 2007), tripolaridad que estructura la antropo-formación, incorporando las transacciones entre los tres polos: relación con el mundo (eco-formación), relación con el otro (co-formación), relación consigo mismo (auto-formación).

Así, para la experiencia investigativa en CEUArkos nos asimos de la nueva visión del mundo y la realidad que nos proveen tanto los pilares transdisciplinarios, como los principios para un pensamiento complejo y la eco-formación, los cuales empleamos para fundamentar y co-crear las estrategias universitarias hacia una perspectiva más integral de la formación. En otras palabras, con estas perspectivas buscamos inaugurar un nuevo periodo para anclar socialmente esta triada conceptual en una comunidad universitaria, tratando de pasar de conceptos de autores a concepciones de prácticas de actores.

\subsubsection{Transdisciplinariedad y Educación Superior}

Como es conocido, en el ámbito educativo, las perspectivas transdisciplinar y compleja han inspirado diversas propuestas universitarias como aquellas del CIRET-UNESCO-Delors (1997) y el Modelo de Janstch (1979). Destacan, también en el plano de lo teórico, los planteamientos de Morin sobre 'Los 7 saberes para la educación del futuro', 'Educar en la era planetaria' y 'A propósito de los siete saberes', que sintetizan los principios de su teoría de la complejidad. Contamos asimismo con las pesquisas de Espinosa y Tamariz (2001) sobre un Modelo de Educación Transdisciplinar para la Universidad y el Modelo de Reynaga (2006) que resume el trabajo de Morin. Pero en el plano de la praxis resaltan las investigaciones del campo de la educación permanente con los trabajos de Pineau (2007) sobre la eco-formación y de Galvani (2007) sobre la autoformación, quienes desarrollan procesos de Investigación-Acción-formación. En 
el ámbito de aprendizaje y conocimiento, las perspectivas más cercanas al ideal transdisciplinario provienen de visiones de autores como Piaget (1980), Maturana y Varela (1998 y 2003) y Galvani (2007), identificadas con el paradigma emergente. Contamos también con importantes aportaciones de autores brasileños como Ubiratan D’Ambrosio (2007), De Almeida (2009), Moraes (2008), así como de los miembros del GRECOM (Almeida y Knobbe, 2003), entre otros.

Empero, el análisis del estado del arte (de 1979 a la fecha) sobre transdisciplinariedad y educación a nivel superior, devela que, las experiencias vivas en instituciones educativas y concretamente en la universidad son aún muy escasas. Disponemos de principios epistemológicos pero no aún de los pasos para la puesta en práctica. De allí que considerásemos que una de las dificultades principales de la puesta en práctica de esta visión más integradora de la formación que ofrece la transdisciplinariedad se encontrara en la carencia de propuestas metodológicas que permitieran hacer operacionales los principios epistemológicos de esta perspectiva en las tareas universitarias y que el paso paradigmático en la universidad había de iniciarse justamente con la formación transdisciplinaria de los diversos actores de la comunidad educativa de que se tratare. En ausencia de modelo, esta formación no puede ser didáctica sino que debe ser experiencial, es precisamente el interés del proceso de investigación-formación-acción el que permite crear colectivamente y reflexivamente los procesos y los contenidos de formación a través de la experimentación misma de los actores.

1.3 La praxis transdisciplinar: El método, un camino que se construye colectivamente

En esta parte presentamos la praxis, las estrategias, los caminos creados colectivamente, el propio método construido por los actores del CEUArkos para una formación transdisciplinar, de allí que consideremos oportuno señalar que aunque el Proyecto Transdisciplinar Arkos está en continuo devenir, fue la necesidad de superar la fragmentación del conocimiento y la formación en el CEUArkos a escala institucional, lo que nos llevó a considerar que la concepción de las prácticas educativas y la forma en que éstas eran llevadas a cabo era lo que estaba en el centro (prácticas a las que subyace una visión de mundo y realidad), por lo que construir caminos sobre cómo operacionalizar la transdisciplinariedad y la complejidad debía darse a través de una indagación conjunta con los actores universitarios. Para ello, era básico iniciar con la propia formación de dichos actores. Es así que uno de los principales propósitos fue formar a profesores y directivos en estas perspectivas, mejorando su cualificación pe- 
dagógica y profesional. Con ellos y con los estudiantes buscamos crear y experimentar, las prácticas y estrategias transdisciplinarias para la formación universitaria.

\subsubsection{Estrategia: Talleres de Investigación-Acción-Formación Transdisciplinarios}

Esta tarea la hemos realizado a través de talleres de I-A centrados en identificar y experimentar los procesos para una formación más integral a partir de la visión transdisciplinar. Es allí que abordamos cómo traducir a pasos metodológicos la transdisciplinariedad y la complejidad para adaptarlos a las prácticas formativas del CEUArkos, intentando liberarlas de la fragmentación.

El objetivo es también encarnar las nuevas corrientes por los actores a partir de prácticas de I-A reflexivas donde cada uno contribuya a la concepción, construcción y evaluación de los caminos explorados (Barbier, 2008; Galvani,2007) pues una evolución tan importante como ir de una lógica disciplinaria a una transdisciplinaria en la universidad no puede desarrollarse brusca y totalmente, sin la participación de los actores y bajo un esquema de sólo transmisión y no de acción-investigación, ya que querer comprender las nuevas perspectivas sin experimentarlas es una contradicción epistemológica.

Los talleres fungen desde el año 2007. Se componen por directivos, profesores, y estudiantes voluntarios (un promedio de 20 personas) de las diferentes esferas del CEUArkos (las disciplinas representadas son: Derecho, Administración y Turismo, Economía, Contaduría, Bioquímica, Ciencias de la Comunicación, Filosofía y letras, Educación, Matemáticas, Mercadotecnia). Están inspirados en los trabajos de Galvani (2007) y Pineau (2007), así como en nuestra propia propuesta (Espinosa y Tamariz, 2001), nacida en una pesquisa anterior. Se basan en nociones como: investigador colectivo, contrato abierto con los participantes (Barbier, 1996); diálogo intersubjetivo y cruzamiento de saberes (Galvani, 2007 y Pineau, 2007); aprendizaje compartido y colaborativo; escucha sensible y multi-referencialidad (Barbier, 2008). Asumen un modelo de reflexión-en-la-acción (Schön, 2006) para trascender la visión de los participantes como meros aplicadores del saber, reconociéndolos como productores del mismo.

\section{El método del taller transdisciplinar}

La formación en el proceso transdisciplinar no debe realizarse bajo un modelo de expertisse y de transmisión sino bajo un modelo reflexivo. El método de los talleres consiste en partir de problemáticas concretas vividas por los participantes, que son analizadas colectivamente en grupos de diálogo transdisciplinarios. Este proceso per- 
mite religar los saberes y la vida en inclusión a la relación del sujeto cognoscente en el objeto de conocimiento. Se trata de una lógica de emergencia donde cada actor del sistema, ya sea profesor, estudiante o administrador, debe participar en la concepción y análisis crítico de los procesos experimentados. Los talleres se constituyen pues por una exploración reflexiva, dialógica y transdisciplinar de problemáticas vividas por los miembros de la comunidad educativa. Considerando que la experiencia vivida es ya transdisciplinar, se toma la opción de partir siempre de situaciones y de problemáticas eco-psico-sociológicas concretas, analizadas dialógicamente entre los diferentes autores, según el proceso siguiente:

Cada participante, profesor o estudiante es invitado a presentar en el grupo una problemática eco-psico-social concreta que él ha observado en su medio y que piensa que debe ser resuelta para las nuevas generaciones.

Estas problemáticas son entonces elegidas por grupos de cinco personas de diferente formación disciplinaria.

En los sub-grupos, cada uno puede perseguir su propia reflexión que generará una investigación personal. Pero el método dialógico implica que cada participante debe construir todas las etapas de su investigación (problemática, recolección de datos y análisis) en diálogo con las diversas disciplinas presentes en su grupo, pero también con personas expertas en los dominios de los saberes pertinentes para el objeto de estudio y que pueden ser exteriores a la universidad, como los saberes populares tradicionales o artísticos. Por ejemplo, si se trata de analizar la problemática de desarrollo de las boutiques para artistas en la "Isla del Río Cuale" -una zona que atraviesa Puerto Valalrta-, no es suficiente interrogar al derecho, la economía, el turismo y la comunicación; es necesario también tomar en cuenta los representantes de los saberes populares tradicionales que hacen de esta isla un lugar fundamental de la cultura local.

En cada presentación de una situación problema, los miembros del taller transdisciplinar, se entrenan en identificar cuáles son las elucidaciones que pueden aportar las diferentes disciplinas pero también los puntos ciegos de cada disciplina. El aprendizaje reflexivo aporta a la vez sobre el objeto de conocimiento pero también sobre la relación del sujeto que conoce con su objeto de conocimiento.

Los grupos de diálogo son seguidos por tiempos de integración, reflexivos, colectivos e individuales.

Para el seminario de tesis transdisciplinar (creado en los talleres de I-A, como veremos más tarde) el mismo método fundamental es utilizado al conjuntar a los estudiantes de todas las licenciaturas en un curso animado y coordinado por un equipo transdisciplinar de 6 profesores. 


\section{-Una pedagogía basada en tres niveles de realidad de la persona:}

Los talleres están orientados a que los participantes desarrollen 3 tipos de aprendizaje ligados a 3 grandes dimensiones o niveles de realidad del sujeto (Galvani, 2007): a) vinculado con el nivel teórico-epistémico o cognitivo, se busca el aprender a pensar, mediante la investigación y a través de los 3 pilares de la transdisciplinariedad $\mathrm{y}$ los 7 principios de la complejidad, intentando generar un pensamiento complejo; b) relacionado con el nivel práctico se enfatiza el aprender a dialogar, distinguir y religar las disciplinas, asumir sus límites y complementos; buscar su interacción a través del diálogo (abierto versus la discusión o la persuasión) y la exploración colectiva; c) Ligado al nivel ético o existencial (reintroducción de las dimensiones sensible y ética), se trabaja con la perspectiva de aprender a aprender sobre el conocimiento de sí mismo, de los propios prejuicios, condicionamientos sociales, históricos y personales de nuestras creencias y certezas, nuestra inspiración y vocación, afinidades, límites y posibilidades, pero también generar reflexiones sobre el conocimiento y el conocimiento del conocimiento. Estos 3 tipos de aprendizaje, inter-ligados, a su vez, a 3 niveles realidad del actuar del sujeto, constituyen lo que podemos denominar los aprendizajes y formas de construcción del conocimiento transdisciplinar para la formación universitaria que exploramos con los miembros del Proyecto Arkos y buscamos llevar a la práctica en las aulas.

-Procesos de los Talleres de I-A-Formación-Transdisciplinar y ejemplos:

En nuestra experiencia una serie de procesos han facilitado el trabajo en los talleres:

a) Procesos de sensibilización y familiarización hacia la transdisciplinariedad y la complejidad debido a que casi ninguno de los integrantes está habituado a ellas. Las actividades iniciales de los talleres se enmarcaron en un proceso de familiarización a la nueva perspectiva - para esta tarea fueron especialmente útiles diversos textos transdisciplinarios (de autores como Nicolescu, Pineau, Galvani, D’Ambrosio), así como la realización de variados ejercicios de diálogo en grupos con representantes de diversas disciplinas-. Se trata de procesos de sensibilización sobre la visión transdisciplinaria y su relación con la teoría de la complejidad; con seminarios de trabajo sobre estas teorías con las personas involucradas en el proyecto.

b) Procesos de identificación de las preguntas de interés de los participantes. La primera propuesta de trabajo que hicimos al interior de los talleres de I-A fue plantear, derivado de la pregunta general de investigación común, preguntas particulares ${ }^{5}$

5 Algunas preguntas fueron: Al ser la motivación una exigencia continua de los estudiantes ¿ ofrece la TD 
por cada integrante que recogieran sus intereses para la modificación y mejora de sus prácticas, para lo cual fue esencial la reflexión en y sobre la práctica (Schön, 2006); los hallazgos y reflexiones sobre estas preguntas se acopiaron por cada uno en un ensayo. Se trató con ello de partir de problemáticas concretas de los actores que serían abordadas desde una perspectiva transdisciplinar (generando así también una producción individual de saber).

c) Consolidación del grupo, a partir de procesos auto-formación y co-formación. La coformación (Desroche, 1982) — producto de un proceso de autoformación colectiva por la investigación cooperativa de producción de saber a partir de una problemática común que concierne a todos y es co-construida- la realizamos en esta investigación a través de la experiencia cooperativa de hacer investigación y reflexión sobre la práctica (acción) con actores de las diversas esferas del CEUArkos y mediante la inter-comprensión necesaria que debió desarrollarse entre los grupos de actores de esas esferas y sus saberes, para lo cual nos servimos del principio dialógico de la complejidad (Morin, 2005) que ocupó un lugar amplio en las actividades que diseñamos, toda vez que fue a través del diálogo que, con los actores, edificamos las diversas etapas de la investigación y emergió el sentido entre las palabras, las acciones y saberes de unos y otros, generando también una sensación de reciprocidad y comunidad en el grupo. El prefijo co, como apunta Pineau (2006, p. 12) “[...] reúne numerosas palabras para intentar expresar relaciones de reciprocidad humana que aparecen, también, como estructurales: relaciones de cooperación, de colaboración, de colegas, de conjunto, de comunidad".

Me anima la posibilidad de discutir estos temas [...] Para mí, es importante tener un lugar de reflexión compartido y promover la reflexión entre los estudiantes, contribuyendo a formar una cultura del debate y del diálogo. Sin conocer exactamente los conceptos de antemano, reconozco en mi formación y en mi actuar ideas de la transdisciplinariedad (crónica \# 2-H, p. 19, Román, Hojas de reflexión, talleres de I-A).

d) Procesos de diálogo intersubjetivo para la apertura y religación de los saberes y

nuevas opciones?; ¿cuáles serían las necesidades de aprendizaje que cubriría la TD?; ¿qué métodos implementar para preparar las clases y exponerlas desde la TD?; ¿cómo incluir las prácticas artísticas dentro del taller transdisciplinario?; ¿qué es el profesor-investigador y qué relación tiene con la TD?; ¿cómo unir el conocimiento científico con el humanismo?; ¿Ser transdisciplinario qué cambios puede lograr a largo plazo, cuál es su impacto social?; ¿Cómo puedo ayudar para resolver los problemas que aquejan a mí comunidad?; ¿Cómo vivir transdisciplinarmente? (crónica \# 2, hojas de reflexión, miembros del taller de I-A) Para ver todas las preguntas planteadas consúltese el anexo B. 
las personas. En un proyecto como éste, en que debe darse especial atención a la comprensión mutua entre los grupos de actores provenientes de las diversas esferas de la universidad, el diálogo resulta básico: "es la práctica que hace emerger un sentido entre las palabras de los unos y los otros [...] [y se vuelve] el lugar de la co-formación, de la reciprocidad" (Galvani, 2008, p. 17). Es por ello que ocupó un lugar ancho las actividades de los talleres. Las sesiones de trabajo permitieron a los integrantes la convivencia con compañeros cuya formación y práctica profesional son, en muchas ocasiones, diferentes a la propia. El trabajo con personas de diferente formación representa además el reto y la oportunidad de aprender a dialogar, distinguir y religar las disciplinas entre sí y con la vida; valorar sus límites, complementariedades y posibilidades de interacción; conduce a una revisión de la propia práctica y del sentido de "comodidad" o "incomodidad" que genera el mantenerse en los límites de una sola perspectiva o de abrirla para aceptar la sabiduría de otras visiones, así como comprometerse con una actitud transdisciplinaria. De allí que para los participantes ello conlleva un ejercicio amplio de tolerancia y apertura:

Cada sesión se convirtió en un ejercicio grupal e individual de diálogo, de tolerancia, de comprensión de nuestras reacciones ante la incertidumbre y la discrepancia con los otros y también de aquello en lo que coincidimos y nos une, la riqueza de nuestra diversidad (crónica \# 2, p. 45, anónima, Hojas de reflexión, talleres de I-A).

Ahora bien, como los trabajos en los talleres parten de problemáticas específicas que viven los participantes en sus contextos, una serie de procesos y dinámicas de diálogo intersubjetivo nos ayudaron en el abordaje transdisciplinar de las mismas. Inspirados en los pilares transdisciplinarios (Nicolescu, 2006) y principios de la complejidad (Morin, 2005), la logística de las sesiones se centra en tres momentos medulares, que se desarrollan alternativamente:

1. Momentos de trabajo y reflexión en subgrupos transdisciplinarios: enmarcados en un diálogo intersubjetivo en el que privilegiábamos el diálogo por sobre la discusión. Los subgrupos, regularmente conformados por tres personas para lograr una interacción real y profunda, buscaron siempre ser TD por lo que en cada sesión buscábamos que los actores compartieran y dialogaran con personas distintas y de formaciones diferentes para permitir el cruzamiento de conocimientos y saberes; los subgrupos no estaban definidos per se, los diálogos versaban sobre: lecturas y videos que abordan temas y autores transdisciplinares; su relación con las prácticas y proble- 
máticas de los actores como parte de la comunidad universitaria, las relaciones con la vida no sólo académica, sino práctica y personal de los mismos. De esos diálogos surgieron diversas estrategias para extender la práctica transdisciplinaria a la universidad en general.

2. Momentos de colaboración-reflexión en plenario. Para evitar monólogos, buscamos la participación de todas las personas mediante la noción del círculo de la palabra Clastres (1971) — una práctica ancestral de culturas antiguas - con el fin de asegurar que todos tuvieran ocasión de expresarse, lo que nos permitió una nueva forma de trascender los puntos de vista particulares y tender a la comprensión mutua entre los participantes.

3. Momentos de trabajo y reflexión individual, consistentes en registrar por escrito los aprendizajes y descubrimientos que cada persona había logrado.

Estos tres momentos (en subgrupo, en plenario e individual) a la manera del bucle recursivo (cuya metáfora es bien representada por el remolino) buscan que los participantes mediante el diálogo con personas de otras disciplinas, analicen y reflexionen colectivamente problemáticas de interés para tener una visión más comprensiva de las mismas tratando de mantener una visión dialógica que permita la vinculación de conocimientos diversos, así como de posturas que se complementan y excluyen. Las actividades buscan la apertura de cada participante a otros saberes y la posibilidad de religarlos al tener como centro una problemática de investigación. Se pone también en juego repensar las desventajas de un conocimiento disgregado, fragmentario y descontextualizado. Diversas dinámicas fueron creadas y experimentadas para desarrollar estos momentos - dinámica de líneas paralelas, dinámica de disparadores de diálogo, dinámicas vinculadas a saberes artísticos; dinámica de la Tortuga (Galvani, 2007), Dinámica de co-desarrollo (Payette), entre otras-.

f) Procesos de exploración, apropiación y profundización en los pilares transdisciplinares y principios complejos: para aproximarse a las problemáticas vividas por los actores y ejercitarse en el manejo de las herramientas del pensamiento complejo, pues se volvieron conscientes de que no estaban habituados a pensar complejamente.

Atendiendo a este objetivo, conformamos subgrupos transdisciplinares para abordar ejemplos de la realidad social, de la praxis en la Universidad o de nuestra práctica profesional disciplinaria, buscando comprenderlas no sólo desde nuestros diversos campos de formación, sino también desde los diferentes pilares y principios. Estas actividades tenían además el propósito de que los actores se ejercitasen en el 
manejo de las herramientas del pensamiento complejo, dado que eran conscientes de que no estaban habituados a pensar complejamente. Con estas ideas en mente, dedicamos tiempo no sólo a establecer relaciones entre el contenido de los textos transdisciplinarios y las prácticas que desarrollábamos, sino también a abordar problemáticas específicas vividas por los participantes en el CEUArkos con el fin de profundizar en ellas, comprenderlas mejor y generar propuestas para su solución, en su caso. Las entrevistas a los participantes muestran cómo en una sesión algunos actores analizaron el problema que presentaban los grupos de la licenciatura en comunicación. Quienes conformaban el grupo transdisciplinar se preguntaron: ¿desde qué puntos podemos analizar esta cuestión? ¿Qué nos aportan los principios de la complejidad?:

[...] yo exponía la [...] problemática de la licenciatura en ciencias de la comunicación $[\ldots]$ me pareció un ejercicio interesante porque pude hacer práctica esa experiencia aplicando los principios. Me permitió recordar [...] lo que habíamos vivido [...] [M] e llamó mucho la atención esta actividad [...] porque estuvimos dos alumnos de la licenciatura [...] un profesor, que es el coordinador [...] y un maestro más que no tenía absolutamente nada que ver con la carrera y que ni siquiera había dado clase a la carrera [...] Yo creo que ahí el trabajo fue muy fructífero, porque por ejemplo, aun habiendo dos personas, que éramos Arturo y yo, estudiantes de la carrera, teníamos perspectivas diferentes, o sea los dos habíamos vivido el proceso de una forma distinta y distinta también a la forma que lo había vivido el profesor [...] y eso a mí me pareció como un ejercicio trans [...] lo más cercano a la TD porque había pluralidad [...] había libertad de expresión y porque de alguna manera evidenciaba la subjetividad [...] con la cual se van desarrollando todos los conflictos [...] y que es [...] pilar fundamental de la teoría de la complejidad (crónica \# 5-A, p. 2, Elías, LCC,4 Entrevistas a estudiantes 2007).

g) Procesos de auto-reflexión y reflexión sobre la inter-experiencia. Los talleres prevén distintos momentos de reflexión y autorreflexión de los participantes para la recuperación de sus experiencias en la praxis transdisciplinar, que son luego objeto de análisis colaborativos.

Si quisiéramos hacer hasta aquí un resumen del procedimiento de trabajo en los talleres de I-A transdisciplinar, podríamos decir que:

-Los participantes parten de una pregunta de investigación de su interés donde abordan problemáticas sociales o aquellas que viven en relación con su praxis universitaria (cada participante establece su propia pregunta).

-Conforman subgrupos transdisciplinares de trabajo con compañeros de di- 
versas disciplinas y realizan una exploración colectiva sobre esa pregunta a través de los aportes de su formación. Se trata de un diálogo entre representantes de diferentes disciplinas, pero también con personas de su misma disciplina.

-La exploración de las preguntas se hace también en los subgrupos mediante el empleo de los pilares transdisciplinares y principios de la complejidad como herramientas que nos ayudan a comprender mejor los procesos y situaciones que son objeto de nuestro interés.

-Luego de trabajar colaborativamente, cada participante tiene espacio para la reflexión individual. Las reflexiones individuales son socializadas más tarde en un plenario.

h) Procesos de producción colectiva de saber. Nos referimos a la creación de estrategias y cursos transdisciplinarios para todas las licenciaturas, validados por la S.E.P., que representan el diezmo transdisciplinario planteado por Morin (2002, p. 89): "ceder un diezmo epistemológico o transdisciplinar que preservaría el 10\% del tiempo de los cursos para una enseñanza común dedicada al conocimiento de las determinaciones y presupuestos del conocimiento, la racionalidad, la cientificidad, la objetividad, la interpretación, los problemas de la complejidad y la interdependencia entre las ciencias." Cursos que en nuestro caso representan el 5\% de la formación universitaria.

\subsubsection{Estrategia: Mesas Redondas/Ferias Transdisciplinarias}

Una segunda estrategia creada colectivamente son las mesas redondas transdisciplinarias que, en palabras de los implicados, constituyen una oportunidad para la praxis transdisciplinar al devenir en una experiencia comunitaria para el diálogo intersubjetivo y la religación de los saberes. Las mesas están dirigidas a toda la comunidad Arkos y son abiertas a la ciudadanía, por lo que se realizan en espacios públicos. En ellas participan: alumnos, maestros, directivos, colectivos y organizaciones sociales, instituciones, artistas, ciudadanos. Son moderadas por los miembros de los talleres de I-A. El objetivo es vivir con las demás personas de la comunidad educativa experiencias transdisciplinarias orientadas a producir mejoras en los procesos de formación universitaria, así como abrir el grupo transdisciplinario, primero hacia el resto de los universitarios del CEUArkos y la comunidad vallartense, con el fin de difundir las nuevas corrientes en el marco de una actividad de diálogo que les permita compartir como seres humanos ideas, intereses y preocupaciones en relación con lo que sucede en su comunidad próxima y lejana.

Las mesas parten de la idea de que diálogo no significa debate ni confrontación directa, sino la manifestación de todos los puntos de vista (Bohm, 2004). Retoman 
como eje problemáticas (sociales, humanas, ambientales, locales y globales) que nos atañen como miembros de la sociedad, que son dialogadas-reflexionadas en pequeños grupos transdisciplinares, a partir de lo cual, los participantes plantean opiniones y propuestas de solución. Las mesas enfatizan el cruzamiento de saberes -académicos, artísticos, populares-. Se trata de abrir el diálogo a los saberes no disciplinarios como los de la experiencia, de lo vivido fenomenológicamente, de la comprensión intersubjetiva e intercultural. Cada mesa transdisciplinaria se compone de 6 a 7 participantes para facilitar el diálogo, se busca que sean personas con diferentes formaciones para asegurar la diversidad (alumnos y maestros de distintas carreras, organismos y personas de la comunidad) interesadas en abordar un tema particular, desde la multiperspectiva.

Como vemos, las mesas replican la dinámica utilizada en los talleres de I-A, sólo que con un número mayor de participantes: revisión de una problemática, diálogo y reflexión en subgrupos transdisciplinarios, reflexión individual y exposición en plenario para compartir los aprendizajes, por lo que el diálogo intersubjetivo (Bohm, 2004) se convierte en una herramienta básica.

Para dar una idea de los temas que se abordan, señalamos que en la primer mesa transdisciplinaria, los miembros de la I-A lograron la participación a un tiempo de 278 personas que conformaron 38 mesas compuestas por maestros, alumnos, directivos y visitantes foráneos. Los asistentes dialogaron sobre 10 temas diversos con características transdisciplinarias como: Crisis de la democracia en México; Apertura y tolerancia en la sociedad actual; Etnias de México ¿civilizaciones sabias o en atraso?; ¿La patria tiene límites geográficos?; Corrupción en el sistema económico; Conflictos causados por disputas de poder; La comunicación en la sociedad global; Calentamiento global y crisis ambiental; Los niños y sus derechos; la educación en México (Crónica \#23-C, Minutas talleres de I-A, 7 marzo 2007).

Con el fin de ilustrar de manera didáctica el tipo de reflexiones que se producen en las mesas transdisciplinarias, presentamos la reflexión colectiva en las que se ve reflejado el sentir y las propuestas de alumnos, profesores y ciudadanos, en ese caso sobre la problemática: Economía versus ecología en el desarrollo de Puerto Vallarta (crónica \# 3-S, p. 23):

Proponemos: desarrollar un pensamiento a largo plazo; reconocer que dependemos de la naturaleza y de sus ciclos; fortalecer el vínculo entre el ecosistema y la cultura con la adaptación al medio ambiente; buscar el contradiscurso, consumir sólo lo necesario; no consumir los productos de quienes se benefician de la concentración urbana, como son: Sams, Home Depot, 
Wall-Mart, etc. [sic]. Por otra parte, observamos que economía y ecología suelen considerarse antagónicas, sin embargo comparten su raíz etimológica "eco" [...] Debemos vislumbrar la posibilidad de un equilibrio, ambas como complemento; es decir, la ecología no debe sacrificarse en aras de la economía. Parte de la solución es la participación ciudadana, el respeto por la naturaleza y la planeación del desarrollo turístico en Puerto Vallarta y mantener bien informado al pueblo. Según hemos visto, el ser humano es el constructor de [cosas que dañan a la naturaleza], suceso que ocurre en detrimento del mundo; por otra parte, no podríamos tener el cinismo de culpar a la naturaleza, nos quejamos del ambiente, de la ignorancia de los demás sin darnos cuenta que el primer ignorante es uno mismo. O tomas conciencia o te destruyes. En suma, proponemos como apuesta la fuerza social, fortalecer el vínculo con la sociedad a través de campañas de información, foros de discusión, exigencias a voz abierta a nuestras autoridades, pedir audiencia pública diaria donde las autoridades tomen las decisiones en función de las necesidades ciudadanas. Acercarnos a colonias populares y comunidades indígenas, medios de comunicación para ejercer presión contra políticas arbitrarias y violaciones a la ley y a los derechos humanos. Exigir derechos básicos como educación, salud, vivienda, trabajo y recreación, habitando un lugar sano y un medio ambiente limpio. Intensificar lo anterior con campañas de información ambientales, y legal, ya que el conocimiento de la ley nos da fuerza [...] para hacerlo [...] y proponer nuevos reglamentos, estatutos o artículos constitucionales. Unir la fuerza ciudadana bajo el principio del eco logos sobre el de eco nomos. Es decir: el espíritu y la razón sobre la norma. Se trata de fomentar la responsabilidad y participación ciudadana para que la información se transforme en acción.

A partir de esta estrategia, hemos co-desarrollado también las Ferias Transdisciplinarias que incluyen, además de las mesas de diálogo, talleres simultáneos que pretenden sensibilizar a los participantes sobre los problemas de orden planetario que enfrenta la humanidad, a través del arte y la cultura popular (talleres de poesía, teatro, artesanía huichol, cine-foros, muestras fotográficas y exposiciones de pintura, entre otros). A la fecha hemos llevado a cabo 11 mesas redondas y 8 Ferias Transdisciplinarias inspiradas en los 7 saberes para la educación del futuro (Morin, 2001).

Las propuestas y aprendizajes logrados durante las mesas y ferias transdisciplinarias son recopilados y difundidos mediante la gaceta de la universidad: Visión Docente Con-Ciencia. La 7a feria realizada se denominó "Por una cultura de paz para la sociedad mundo", la experiencia puede consultarse en: Urrutia y Miembros del Taller Transdisciplinar Arkos (2014) http://www.ceuarkos.com/Vision_docente/septima\%20feria.pdf 


\subsubsection{Estrategia: Seminarios de Tesis Transdisciplinarios}

La tercera estrategia co-construida son los seminarios de tesis transdisciplinarios, dirigidos a los estudiantes del IX cuatrimestre de todas las licenciaturas del CEUArkos (Contaduría, Derecho, Administración de Empresas Turísticas, Ciencias de la Comunicación, Mercadotecnia). Los objetivos de estos seminarios son: el abordaje, mediante la investigación, de problemáticas de la realidad que afectan a la comunidad en que los estudiantes están inmersos; construir tesis con perspectiva transdisciplinar; asumir tanto las virtudes como los límites de las áreas de formación. Buscan (al igual que los talleres de I-A) desarrollar en el estudiante 3 tipos de aprendizaje ligados a 3 dimensiones o niveles (de realidad del sujeto): dimensión epistémica-aprender a pensar; dimensión práctica-aprender a dialogar; dimensión ético-existencial-aprender a aprender.

Para operacionalizar los seminarios constituimos colectivamente:

a) Un equipo docente transdisciplinar conformado por miembros de talleres de I-A (en el primer seminario, por ejemplo, participaron 5 docentes de formaciones diversas: un contador, un abogado, un economista-administrador, una profesora en letras y un filósofo).

b) Grupos mixtos con alumnos de las diferentes licenciaturas;

c) Un plan de tesis con sentido transdisciplinar: Las tesis deben abordar problemáticas de la realidad (social, humana, ambiental). La base transdisciplinar se da por incorporar pilares transdisciplinares y principios complejos como herramientas metodológicas para tratar la problemática de investigación. Deben ser producto del análisis e interacción del estudiante(s) con el objeto de estudio y de un proceso de acompañamiento dialógico del mismo, dado por las estrategias intersubjetivas, reflexiones colectivas y trabajo colaborativo entre disciplinas. Deben también incluir investigación de campo.

Los procesos de los seminarios son similares a los de los talleres de I-A. Los estudiantes eligen una problemática concreta que observaron en su medio y querrían ver mejorada para las generaciones futuras. Estas problemáticas son entonces exploradas por grupos de estudiantes provenientes de las diferentes disciplinas del CEUArkos. El diálogo de disciplinas se hace a partir de la especificidad de los puntos de vista, tratando de comprender cómo cada disciplina está relacionada a la problemática concernida. Ver qué soluciones aporta pero también cómo contribuye a alimentar los problemas a causa de sus límites y sus puntos ciegos. Las tesis pueden ser individuales 
o colectivas, según la elección de los estudiantes. En cualquier caso, cada participante (o grupo de participantes) persigue su propia investigación, pero debe construir cada etapa de la pesquisa en diálogo con las otras disciplinas y fuentes de saber pertinentes para su problemática. Se trata, por tanto, de una experiencia cooperativa de aprendizaje para la producción de saber individual y colectivo. Los saberes pertinentes no se limitan a las disciplinas científicas, se abren al arte, la filosofía, saberes populares. Con esta experiencia, vemos a los universitarios aproximarse a problemáticas que salen del dominio de los campos técnicos de las licenciaturas, que reconocen la riqueza y complejidad de las problemáticas que conforman la realidad. Las investigaciones se arraigan en las problemáticas sociales, ambientales cotidianas que conocen los estudiantes y que los tocan personalmente o familiarmente. No se trata ya, de problemas teóricos abstractos o especializados que levantan la lógica interna de la disciplina sino de problemas arraigados en la vida que demandan la vinculación y religación de los saberes disciplinares para abordar las realidades complejas.

En las siguientes líneas presentamos algunos ejemplos concretos de las investigaciones transdisciplinarias desarrolladas y defendidas por los estudiantes ante jurado, con las cuales lograron su titulación. Los abstracts se tomaron de la reciente participación que los jóvenes tuvieron en la presentación del libro: "Abrir los saberes a la complejidad de la vida. Nuevas prácticas transdisciplinarias en la universidad" (Espinosa, 2014):

\section{Investigación 1}

- MI NOMBRE ES: Rubén Chavarín.

- EGRESÉ DE LA LICENCIATURA EN: Derecho.

- LA TESIS CON QUE ME TITULÉ SE LLAMA: Implicaciones económicas y sociales en la comunidad Indígena de Chacala, a partir de la reforma agraria del art 27 constitucional.

- LAS PREGUNTAS PRINCIPALES DE MI INVESTIGACIÓN FUERON: ¿Cuáles son los beneficios o perjuicios que trae consigo la reforma agraria al artículo 27 de la constitución política a esta comunidad?, ¿cuáles son las implicaciones sociales y económicas de la reforma que modifica el régimen comunal?

- PROBLEMÁTICA: Con la reforma agraria al artículo 27 se establece que comunidades como la de Chacala, del Municipio de Cabo Corrientes, Jalisco, cuyo régimen es comunal, pueden realizar actos jurídicos como una persona física, al llevar a cabo los procedimientos establecidos en la ley. Ello 
permite que las tierras puedan cambiar su régimen y considerarlas como pequeña propiedad, lo cual, a su vez, hace posible, por ejemplo, la venta de las tierras. A partir de ello, una serie de eventos se han suscitado en la comunidad, que ponen en juego tanto la decisión de sus miembros de vender o usufructuar las tierras a terceros, como también ponen en juego el sentido de comunidad, pues, según los pobladores, en ocasiones diversas, se han presentado a la localidad personas ajenas a la misma, a saber inversionistas, con el interés de adquirir o arrendar las tierras para la realización de complejos turísticos, principalmente, dada la belleza de las playas chacalenses, y en general, de su riqueza en flora y fauna, despertando variedad de intereses y pugnas entre los habitantes.

- LOS DIFERENTES TIPOS DE SABERES QUE UTILICÉ FUERON: saberes del ámbito del Derecho que crucé con conocimientos del ámbito económico y social, así como de historia del régimen comunal y de la propia comunidad indígena de Chacala.

- EL TRABAJO DE CAMPO INCLUYÓ: Encuestas y entrevistas con personas de la comunidad, observación directa de la realidad del lugar, asistencia a asambleas de comuneros y recopilación de documentos de la comuna.

\section{Investigación 2}

- NUESTROS NOMBRES SON: Edgar Palacios y Mónica Castillón.

- EGRESAMOS DE LA CARRERA DE: Administración de Empresas Turísticas.

- NUESTRA TESIS SE TITULÓ: Investigación sobre la situación actual del estero "El Salado". Impacto socio-ecológico y potencial de un Desarrollo Turístico Sustentable.

- LAS PREGUNTAS CENTRALES DE NUESTRA INVESTIGACIÓN FUERON: ¿Tiene el Estero El "Salado" el Potencial para un Desarrollo Turístico Sustentable (DTS)? ¿Qué impactos sociales y ambientales conllevaría la realización de un DTS en el Estero "El Salado"?

- CONTEXTO: Realizamos la investigación con la finalidad de identificar los principales problemas de contaminación, intereses económicos y carencias en planeación urbana que aquejan actualmente al estero "El Salado" (Área Natural Protegida-APN-), impidiéndole su buen desarrollo; así como de investigar su potencial turístico sustentable, analizando las características actuales del área, identificando las zonas con mayor biodiversidad de flora 
y fauna, que pueden ser atractivas para los turistas.

Sabemos que el municipio de Puerto Vallarta tiene como industria principal al turismo; actividad que puede contribuir a la conservación del Estero, generando recursos económicos que al mismo tiempo ayuden a disminuir algunos de los problemas que la zona presenta actualmente, garantizando la conservación del ecosistema y beneficiando a la comunidad local ambiental y económicamente.

- EN CUANTO A LOS DIFERENTES TIPOS DE SABERES: En la realización del estudio abordamos el problema desde disciplinas como Mercadotecnia, Ecología, Derecho y Turismo, así como desde el análisis la cultura y prácticas sociales de grupos ciudadanos en el municipio de Puerto Vallarta.

- EL ESTUDIO DE CAMPO INCLUYÓ: Observación del Estero y alrededores; Encuestas a población en Puerto Vallarta; Entrevistas a especialistas como: una Oceanóloga, Biólogo, Personal de la Oficina de Turismo; Contrastación y análisis del área natural protegida (ANP) denominada Laguna de Términos con DTS versus El Salado, Recopilación fotográfica y vídeos.

\section{Investigación 3}

- MI NOMBRE ES: Carolina Sandoval.

- EGRESÉ DE LA CARRERA DE: Derecho.

- MI TESIS SE TITULÓ: Reglamentación jurídica para la legalización de la adopción entre parejas homosexuales en el estado de Jalisco.

- LAS PREGUNTAS PRINCIPALES DE MI INVESTIGACIÓN FUERON: ¿Cuáles son los factores que han impedido que se legalice la adopción entre parejas homosexuales en el estado de Jalisco? ¿De qué manera favorecería a la regulación de la adopción, que se regulara el matrimonio por parejas homosexuales?

- CONTEXTO DE LA INVESTIGACIÓN: Acreditar la igualdad entre homosexuales y heterosexuales, en términos de sus derechos; Acreditar que un menor no sufre trastornos preocupantes por los cuales no pueda vivir con parejas homosexuales; Demostrar que no existe motivo suficiente por el cual no se legalice la adopción entre parejas homosexuales en el estado de Jalisco y por tanto en Puerto Vallarta. Analizar la discriminación que esta laguna jurídica lleva implícita.

- SOBRE DIFERENTES TIPOS DE SABERES: Comento que la investigación la realicé desde una perspectiva jurídica, pero también analicé la visión re- 
ligiosa, dado que tiene un gran peso en la sociedad mexicana y particularmente en la jalisciense, revisé las perspectivas: educativa y psicológica y el impacto de los medios de comunicación; analicé estudios sobre género.

- INVESTIGACIÓN DE CAMPO: Realicé encuestas a adultos (varones y mujeres) y a menores de edad (varones y mujeres) de nivel secundaria en Puerto Vallarta. Realicé visitas a diversas dependencias y casas hogares para observación y para entrevistas respecto de los procedimientos de adopción. Entrevisté también a un Juez de primera instancia, a un cura y un psicólogo. Trabajé con el método de historias de vida con personas homosexuales.

\section{Investigación 4}

- MI NOMBRE ES: Arturo Arteaga.

- EGRESÉ DE LA LICNCITURA EN: Ciencias de la Comunicación.

- MI TESIS SE TITULÓ: Creación del Macro-libramiento en Puerto Vallarta, afectaciones sociales y ecológicas en las zonas en que se construirá.

- LAS PREGUNTAS DE MI INVESTIGACIÓN FUERON: ¿Qué afectaciones sociales y ambientales tendrá la ejecución del proyecto del macro-libramiento? ¿Qué rol juegan los medios de comunicación en la documentación y divulgación de esta problemática hacia la población?

- SOBRE LOS TIPOS DE SABERES QUE UTILICÉ DEBO DECIR QUE: Esta carrera (Ciencias de la Comunicación) es el mejor ejemplo de un sistema transdisciplinario, la investigación la realicé desde distintas perspectivas, como lo son: ecológica, política, económica, comunicacional..., haciendo énfasis en el ámbito social, ya que todo repercute en ello.

- EL TRABAJO DE CAMPO INCLUYÓ: Monitoreo de distintos medios de comunicación (radio, periódicos, gacetas y sitios oficiales, internet) sobre la problemática. Actividades de observación de la zona. Entrevistas con las personas afectadas por el proyecto, así como con funcionarios públicos involucrados. Análisis de entrevistas con investigadores del Grupo Ecológico "Nuestra Tierra".

\section{Investigación 5}

- MI NOMBRE ES: Guadalupe Pámanes.

- EGRESÉ DE LA CARRERA DE: Ciencias de la Comunicación.

- MI TESIS SE TITULÓ: Sobre-sexualización de la imagen de la mujer en Puerto Vallarta. Cosificación y objetualización de la mujer en los ámbitos 
laborales turísticos y lugares recreativos; bares y 'antros' de Puerto Vallarta, analizando los conceptos de buena imagen y buena presentación.

- CONTEXTO DE LA INVESTIGACIÓN: El interés del estudio es analizar (desde una perspectiva teórica y también práctica) las causas del fenómeno de la sobre-sexualización de la imagen de la mujer en Puerto Vallarta, para desenmarañar el cúmulo de significados que gira en torno a las nociones de buena imagen y buena presentación, requisitos claves en la mayoría de los empleos para mujeres, que muchas veces llegan a desacreditar las capacidades de la persona.

- EL TRABAJO DE CAMPO INCLUYÓ: prácticas de observación en lugares recreativos (bares y antros) y entrevistas con mujeres que viven de cerca el fenómeno o lo han padecido, entre ellas, edecanes, y hostess en lugares como restaurantes y bares.

- LOS DIFERENTES TIPOS DE SABERES QUE UTILICÉ FUERON: saberes desde el ámbito de la antropología y la sociología, partiendo de la noción de cultura e identidad, revisé particularmente estudios sobre género, que crucé también con conocimientos sobre comunicación.

\subsubsection{Estrategia Talleres Transdisciplinarios con Estudiantes}

Derivado de los seminarios de tesis transdisciplinares se constituyeron los cursos denominados talleres transdisciplinares para estudiantes, con grupos mezclados de todas las licenciaturas, talleres que, a la vez que apuntalan a los seminarios, comparten las mismas orientaciones pedagógicas que éstos, pero que buscan la apropiación de los principios de la complejidad, la visión transdisciplinar y sus pilares de forma más lúdica, mediante el cruzamiento de los saberes de la experiencia, los saberes artísticos y los saberes populares (sin desatender los saberes teóricos) y que tienden a construir proyectos transdisciplinares colectivos de servicio a la comunidad guiados por la triada individuoßàsociedadßànaturaleza y los siete saberes necesarios para la educación morinianos. Por ejemplo, las problemáticas sociales, ambientales y humanas, tratadas en sus tesis y la aplicación de los principios de la complejidad a las mismas, son abordadas en grupos transdisciplinarios mediante representaciones teatrales, ensayo, cuento, pintura, poesía, música, medios audiovisuales, etc. Se realiza trabajo de campo en diversas zonas de la ciudad para revalorar el saber experiencial y la historia oral, mediante la práctica del método de las historias de vida. Asimismo se generan proyectos de atención a necesidades de diversos grupos sociales, particularmente vulnerables (adultos mayores, niños en situación de calle o en orfandad, reclusas, enfer- 
mos) mediante talleres y actividades de convivencia en los que se ejercitan los 7 saberes propuestos por Morin; hay proyectos también de reforestación de las comunidades en las que viven o del cuidado del entorno, de construcción de bibliotecas itinerantes, de actividades de asesoría (en sus áreas de formación) abiertas al público en plazas públicas, de rehabilitación de escuelas en zonas rurales, talleres de re-uso y reciclaje, se plantean retos de acciones cotidianas para el cuidado del triángulo de la vida (D’Ambrosio, 2007), entre otras.

Los seminarios de tesis transdisciplinarios y los talleres transdisciplinarios para estudiantes representan, como señalamos antes, el diezmo curricular transdisciplinar del CEUArkos, pues han sido incluidos en el currículo oficial de los programas de estudio de todas las licenciaturas de la universidad, los cuales han sido validados y reconocidos por el ministerio de educación mexicano (S.E.P.), como parte de la formación universitaria en la institución. Son pues parte del proceso de institucionalización de la transdisciplinariedad y la complejidad en la universidad.

\subsubsection{Estrategia: Ejercicios Transdisciplinarios en las Aulas}

Otra estrategia es lo que los actores denominaron los ejercicios transdisciplinarios en las aulas, dirigidos a todos los estudiantes del CEUArkos. Estos ejercicios buscan: sensibilizar a los alumnos de las diversas carreras hacia una perspectiva más planetaria de la praxis del hombre en el mundo; gestar una actitud transdisciplinar en la población estudiantil y prepararla hacia las ideas de esta nueva perspectiva, antes de tener la experiencia formal de un curso transdisciplinar.

La intención de esta estrategia es despertar tempranamente una actitud transdisciplinar en las aulas, situación que buscamos construir a partir de ejercicios vivenciales, crítico-reflexivos sobre diversos campos de interés transdisciplinar (desarrollados en las aulas o en espacios foráneos). Estos ejercicios se apoyan fuertemente en el uso de saberes artísticos (teatro, poesía, fotografía, literatura, música); saberes populares (como el círculo de la palabra -Clastres, 1971-) y dinámicas de diálogo (Bohm, 2004). La dinámica de trabajo se divide en 6 momentos: a) ejercicios de sensibilización, b) Lecturas breves de textos transdisciplinares, c) reflexión en subgrupos pequeños mediante diversos ejercicios, d) reflexión individual sobre los aprendizajes de la sesión, e) socialización de las reflexiones y diálogo plenario.

Las memorias de Romina, una profesora participante de los talleres de I-A, describen bien la logística de los ejercicios transdisciplinares y la respuesta obtenida en las aulas: 
Recuerdo con grato agrado la sesión transdisciplinaria que Mandy (un alumno miembro de los talleres de I-A) y yo tuvimos con el grupo de VI cuatrimestre de Contaduría, me sentía un poco nerviosa pues además de que entramos como "bateadores emergentes", nos tocaba "enfrentar" a los contadores que según dicen los expertos son poco abiertos a estas cuestiones, porque tienen un perfil muy particular. El tema a compartir: la incertidumbre. Iniciamos haciendo una breve presentación sobre el motivo de nuestra presencia, luego se repartió el material y se explicó la logística, estábamos en la sala audiovisual, había alrededor de 15 asistentes, para romper el hielo, se inició solicitándoles, que de manera individual, escribieran los momentos que habían sido más significativos en su vida y que luego distinguieran si éstos habían sido planeados o fortuitos, luego en plenario les pedimos si querían compartir algunos de esos momentos, pero ninguno accedió, así que sólo Mandy y yo los compartimos, después se formaron subgrupos de 3 integrantes y sobre una serie de preguntas estructuradas se inició con el diálogo. Me agregué a un subgrupo de 3 caballeros y la experiencia resultó gratificante, pues nunca antes había tenido oportunidad de intercambiar con ellos ideas, formas de pensar. Durante el diálogo se fueron abriendo poco a poco, comentaron cosas de su vida familiar, personal, de sus aspiraciones, de sus miedos, de sus sentimientos, de sus necesidades, con alguien que les era bastante ajeno. Para redondear lo vivido ... escuchamos la canción "qué será, será", para entonces se habían consumido $1 \mathrm{hr}$ y 20 minutos, aún faltaba la faena más larga, la lectura del resumen, pero ellos mostraban gran disposición de continuar, tuvimos que salir de la sala y pasarnos a su aula donde continuamos con la lectura comentada e intercambio del resumen, finalmente ... llegó el momento de agradecer y pedirles la reflexión escrita, mi mayor momento de felicidad fue al leer las reflexiones individuales donde el común denominador era lo grato que les había parecido la sesión y nos solicitaban se hiciera más a menudo, inclusive algunos manifestaban que les había servido como "catarsis", para desahogarse de lo cotidiano... (crónica \#9-A, p.4, Romi, puerta de la felicidad).

A fin de dar una idea de la diversidad de los ejercicios transdisciplinarios que fueron llevados a cabo en todas las aulas del CEUArkos presentamos un par de ellos (crónica \#22, Ejercicios transdisciplinarios construidos en los talleres de I-A).

Por ejemplo, un equipo conformado por dos profesoras y un estudiante ideó el siguiente ejercicio para el tema de 'Las cegueras del conocimiento: el error y la ilusión' que trabajó con un grupo de alumnos de la Licenciatura en Ciencias de la Comunicación (tema que es parte del texto 'Los siete saberes para la educación del futuro' de Edgar Morin, 2001). Los autores de esta actividad describen su plan general y las prácticas que llevaron a cabo de esta forma: Momento I. Ejercicio breve de sensibilización: Se plantearon tres posibilidades al grupo a elegir: a) Canción: la maldición de la Malinche; 
b) Poema: Ajedrez, de Borges; c) Texto: "De las 3 transformaciones" de Nietzsche. Según los actores, se eligieron estos textos porque introducen las ideas de los niveles de realidad (Pilar de la transdisciplinariedad, según Nicolescu, 1998) y las cegueras del conocimiento (vinculadas a los principios de la complejidad -Morin, 2001, 2003, 2005); Momento II. Lectura del resumen del capítulo I del libro de Morin (2001) sobre las cegueras del conocimiento; Momento III. Reflexión en subgrupos pequeños sobre el punto I y II mediante el ejercicio de frases incompletas sobre Las cegueras del conocimiento; Momento IV. Reflexión Individual sobre la sesión, luego de la reflexión intersubjetiva que después fue socializada.

Otros ejercicios tuvieron como marco lugares distintos al aula, por ejemplo el profesor Marco, Arturo un estudiante y Jezabel, una maestra, acudieron con un grupo de Derecho y otro de Comunicación a un espacio abierto, con el fin de introducir las ideas sobre 'La ética del género humano', para lo cual incluyeron un ejercicio vivencial de contemplación (en la Isla del Río Cuale -cercana a la universidad-) que consistió en acercarles a la naturaleza a fin de explorar el bucle individuoßàsociedadßàespecie planteado por Morin (2001) y D’Ambrosio (2007), como eje de las relaciones éticas del ser humano consigo mismo, con los otros y con el medio ambiente. A partir de ello, organizaron diálogos para analizar grupalmente su experiencia y retomaron frases de textos vinculados con el tema. Luego realizaron el ejercicio llamado 'el cadáver exquisito o el fluir de la conciencia' -que retoma la idea de épochê de Husserl y de libre pensamiento de Breton (en Moret, 2004) -porque al escribir desde el anonimato era posible que aflorase lo que las personas realmente piensan y sienten: "podríamos hacer un cadáver exquisito o de fluir de la conciencia -me gusta más porque me encanta cómo funciona el anonimato para sacar lo que llevamos dentro-" (crónica \#2-A, p.43, Jezabel, Hojas de reflexión miembros talleres de I-A). La posibilidad de que los estudiantes se expresaran con libertad permitió el paso trascendental de trabajar con las ideas de enseñar la comprensión y la tolerancia, que sugiere la actitud transdisciplinar (Carta de Arrábida, 1994) y dio oportunidad de comprender a los estudiantes mediante sus propias voces, recurriendo a la fenomenología.

2. Abrir los saberes a la complejidad de la vida: nuevas prácticas transdisciplinarias en la universidad.

La institucionalización de la transdisciplinariedad y la complejidad en los procesos del aprendizaje, de la enseñanza y de la investigación en el CEUArkos, muestran 
la factibilidad de llevar a la práctica estas perspectivas y el enriquecimiento que las mismas generan en dichos procesos y en sus actores. Asimismo, evidencian la necesidad de abrir los saberes académicos a la complejidad de la vida, de religarlos con las problemáticas del entorno (natural, humano, social) y con otro tipo de saberes como aquellos de la experiencia vivida, los saberes artísticos y populares, entre otros. Lo que continuación presentamos incluye aquello que emerge de la puesta en práctica de las estrategias transdisciplinarias construidas colectivamente, un breve análisis de sus resultados y recomendaciones.

2.1 Qué emerge con la puesta en práctica de la transdisciplinariedad y la complejidad

Partiendo de la pregunta ¿qué emerge, en la personas y en los procesos formativos, con las estrategias transdisciplinarias construidas colectivamente?, diremos que los datos de la investigación arrojan una serie de cambios en los procesos universitarios y en las personas involucradas en ellos. En el aprendizaje visualizamos cambios significativos, en el ámbito epistémico para aprender a pensar complejamente la realidad a través de herramientas nuevas, a saber los pilares transdisciplinares y los principios complejos (Nicolescu, 1998; Morin, 2005). En este mismo ámbito los participantes de las diversas estrategias señalan que son capaces de observar la realidad desde una perspectiva compleja, asumiendo su pluralidad y de abordar las problemáticas de la realidad desde la multiperspectiva y la multirreferencialidad. Adquieren saberes formalizados de otras disciplinas, aprenden a contextualizar y establecer relaciones entre el todo y la parte en los fenómenos, gracias al trabajo cooperativo entre disciplinas. Un aprendizaje colaborativo emerge como esencial en la formación. Por otro lado, en las personas surge la conciencia de la complejidad humana en la que están presentes comportamientos contradictorios y diversos niveles de realidad (del sujeto), comprenden que somos a la vez físicos, biológicos, síquicos, culturales, sociales, históricos, planetarios. Un nuevo concepto de conocimiento, como abierto, inacabado y susceptible de error, lo vemos también surgir en sus reflexiones. Los participantes manifiestan ser capaces de identificar cegueras del conocimiento, entendidas como falsas ideas y creencias y concienciar cuánto nos manipulan. Una nueva noción de método como camino que se construye se gesta. Aparece también la conciencia de que necesitamos una racionalidad abierta que va más allá de la razón que nos brinda la ciencia.

Por otra parte, asistimos a cambios sobre el aprendizaje práctico consistentes en el aprender a dialogar, distinguir y religar a las personas y distintos tipos de sabe- 
res bajo una noción de diálogo abierto (Bohm, 2004; Galvani 2007b; Pineau, 2007b; Morin, 2005) por sobre la discusión, el diálogo emerge como herramienta a través de la que se edifica la I-A, pero también como medio para intercambiar ideas, aprender colectivamente, generar nuevas estrategias y significados. El trabajo continuo en grupos transdisciplinares con personas diversas y de áreas de formación distintas, gesta vínculos de los miembros de la comunidad universitaria entre sí y luego de éstos con la sociedad vallartense; ayuda, según los participantes, al partir de problemáticas de interés de las personas, a ejercitarse en el cruzamiento de conocimientos académicos, a la religación de éstos con otro tipo de saberes (como los artísticos y populares), a tender puentes entre las asignaturas del currículo y desarrollar acciones que interligan teoría-práctica-ética. Los actores apuntan que la experiencia transdisciplinaria permite luchar contra las barreras de comunicación entre las disciplinas, contra su babelización (según Nicolescu, 1998). Destacan que aprenden a expresarse y a escuchar a los demás y desarrollan actitudes de tolerancia y apertura ante otras personas y visiones, que les ayudan a lidiar con situaciones difíciles, a comprenderse y comprender a otros.

Por otra parte, con esta I-A, un espacio importante se abre en el ámbito de la auto-formación, al aprendizaje ético-existencial (Barbier, 1996; Galvani 2007) a partir de promover en la universidad aprendizajes sobre el conocimiento de sí mismo y sobre el conocimiento del conocimiento (Morin, 2006). Abrir este espacio se vincula, para los actores, con un sentido ético de ser corresponsables en una sociedad; pero también en el mantenimiento y cuidado de la vida (conciencia planetaria). Al trabajar con la transdisciplinariedad emerge en los actores (de los talleres) un nuevo concepto de educación: como una visión ética, humanista y planetaria de la práctica y la formación universitaria, que apela a una ética de la formación universitaria no reduccionista: no restringida a la formación académica y profesional, sino incluya comprender la condición humana, como parte de la formación. Situación que los alumnos (de los seminarios de tesis) traducen como visión humanista que trascienda el esquema de los títulos, rompiendo con el 'fantasma' o 'máscara de las carreras' y reconocer que se requiere una ética de la praxis humana sobre el mundo.

En los participantes vemos también aparecer un cuestionamiento al modelo socio-económico actual tendiente al consumo, al materialismo, la competencia, la degradación de culturas y a deshumanizar las relaciones entre personas. La emergencia de actitudes reflexivas de introspección, de autocrítica y la asunción de participar en diversos niveles de realidad, está también presente como una conciencia de sí. Se trata de la emergencia de una ética recursiva, entendida como asumir nuestra capacidad para cambiarnos a nosotros mismos. Los participantes acotan que apren- 
den a identificar los propios prejuicios que emergen de sus tradiciones cognoscentes y modelos de actuar. Las experiencias con transdisciplinariedad, en sus palabras, ayudan a generar comprensión y empatía entre las personas y a asumir las incertidumbres como parte de la vida. Por último, vemos a las personas interesarse por el conocimiento del conocimiento y reflexionar en la educación este aspecto ha de convertirse en prioritario.

En el ámbito de la enseñanza, vemos que los procesos de sensibilización y familiarización a las nuevas corrientes se caracterizan por momentos de curiosidad y expectación de los participantes, así como de resistencia e incertidumbre hacia lo nuevo y lo desconocido; a no contar (en el caso de los maestros) con un método pedagógico transdisciplinario construido per se como se está acostumbrado dentro del paradigma aún instalado de la ciencia aplicada (que invita no a construir saber sino a consumirlo, Schön, 2006); a encarar el rompimiento de un modelo docente que 'conoce todo', a no tener la respuesta correcta y pensar la descalificación de la disciplina. Empero, esas situaciones son trascendidas poco a poco mediante el acompañamiento y trabajo colectivo entre los distintos participantes. Éstos señalan que son capaces de lidiar con la incertidumbre mediante el ejercicio de actitudes de tolerancia y apertura ante otras personas y perspectivas, pero también dado que advierten la necesidad de un cambio en la educación que atienda a una visión no sólo humanista sino planetaria de la vida. Con esta I-A vemos que la resistencia llega a convertirse en un instrumento dinámico que dispara la curiosidad y el interés de las personas por construir algo nuevo y en un proceso recursivo que ayuda a comprender que el acercamiento a las nuevas corrientes en las aulas estará imbricado de esas mismas características.

En la enseñanza observamos también una orientación a la co-formación o la enseñanza cooperativa entre distintos tipos de actores y saberes (Pineau, 2007; Declaración de Vitória, en Espinosa 2005) el acento queda puesto no sólo en los contenidos sino en los procesos y las relaciones entre personas, disciplinas, asignaturas y fenómenos de estudio (Galvani 2008; Moraes, 2008). Un espiritu cooperativo y la constitución de una comunidad de aprendizaje, a partir del trabajo colectivo se pone en práctica.

La enseñanza se basa en procesos de interrelación y complementariedad entre diversos conocimientos, posturas y perspectivas. Se abre al uso de diversos saberes académicos y no académicos y promueve en las aulas experiencias que generan vínculos entre intelectualidad, emotividad y corporeidad. Asimismo el diálogo dialógico intersubjetivo y la reflexividad se convierten en herramientas que permiten ejercer una ética retroactivo-recursiva sobre los procesos de formación entre los actores implicados .

En el ámbito de la investigación destaca: la emergencia del rol investi- 
gador como parte de la tarea docente, estudiantil y directiva; la conversión de problemáticas de la realidad en que se inscriben los actores en objetos de pesquisa y una cooperativa para la producción de saber (Desroche, 1982) que lleva a la universidad, sus miembros y saberes a vincularse entre sí y con su entorno (eco-formación). La noción de implicación de los sujetos en las problemáticas emerge en los participantes de las 4 estrategias. La vida social de la comunidad en que se inscriben los universitarios así como el entorno natural y las problemáticas que de ellos se derivan, se convierten en objeto central de los aprendizajes gestados en las diversas disciplinas ofertadas en CEUArkos, produciéndose una tendencia hacia la ecologización del saber y la formación universitaria. Se trata de ligar la investigación con la vida. Por ejemplo, en los seminarios de tesis los estudiantes se adentran en problemáticas de su comunidad y las retoman para sus investigaciones. Se trata de problemáticas complejas que demandan la religación de saberes y ponen cada vez más en primer plano el orden social y comunitario (conciencia social). Asimismo vemos surgir en las tesis, con mayor frecuencia y en todas las disciplinas, la dimensión medioambiental así como un cuestionamiento crítico y autocrítico sobre la producción de los desequilibrios ambientales que generamos con la nuestra praxis y saberes. Las pesquisas, recuperación también el saber inscrito en las personas que viven las problemáticas.

Los participantes (particularmente de los talleres de I-A y seminarios de tesis transdisciplinares) señalan que se generan: cambios en su visión de la disciplina, a la que buscan trascender abriéndose otras y reconociendo sus límites y fortalezas; cambios en la praxis profesional, asumiéndola como no aislada de lo social y advirtiendo nuevos escenarios de actuación; cambios que trascienden la disciplina y se dirigen hacia la vida cotidiana en los ámbitos familiar, social, personal, pues conciben la transdisciplinariedad como estilo de vida que liga ideas, actos y ética; cambios en la praxis pedagógica: desde modificar los referentes teóricos de la práctica docente y los cursos, hasta los estilos de enseñar abriéndose a nuevos saberes y recursos, dar espacio a la manifestación de sentimientos en el aula, etc. Vemos también un nuevo rol docente no como mero transmisor, ni poseedor de todo el saber, sino acompañante-guía en los procesos de formación; y de un rol del estudiante como activo, capaz de construir su propio conocimiento y reflexionar sobre lo que aprende. 


\subsection{Conclusiones}

\subsubsection{Un camino a la Auto-Eco-Re-Organización de la Universidad}

La presente investigación trascendió la noción de interdisciplinariedad, operacionalizando la transdisciplinariedad con base en la perspectiva de Nicolecu (1998) y de Edgar Morin (2005). - citada por Klein 2013-

Con esta investigación aprendemos que transdisciplinariedad y complejidad más que un escenario cómodo representan un escenario cuestionante para las personas en sus distintos niveles de realidad, pues llevan al rompimiento de paradigmas; cuestionan hábitos y costumbres enraizadas en nuestras formas de ser, actuar pensar, por lo que generan procesos acercamiento/distanciación a las nuevas corrientes. Se trata de entender que el camino a la transdisciplinariedad no está exento contradicciones, sigue no un proceso lineal sino discontinuo de incertidumbreßàresistencia ßà tolerancia ßà apertura de los actores y sus prácticas. Empero, la transdisciplinariedad en la universidad es posible siempre que ésta y sus miembros se asuman como sistema abierto, como una comunidad de aprendizaje que renuncia a la certidumbre de haber alcanzado la verdad y asume la noción de regenerarse constantemente. Sin duda la búsqueda por operacionalizar la transdisciplinariedad y la complejidad en el CEUArkos se convirtió en una experiencia de auto-eco-re-organización de la universidad toda vez que el proyecto se realizó a escala institucional; se edificó con la participación de representantes de todas las instancias universitarias y las estrategias construidas impactaron todas las licenciaturas, lo que implicó procesos auto-eco-re organizadores de las relaciones entre actores y sus prácticas.

\subsubsection{Investigación-Acción: Método propicio para Generar Escenarios Transdiscipli-} narios

Con la I-A aprendimos también que: el camino a la transdisciplinariedad es un tránsito lento que se asienta en la disposición, interés, libertad y voluntad de las personas para construirlo; que es trascendental partir de problemáticas reales y significativas vividas por miembros de la comunidad universitaria; y que crear un espacio abierto para la reflexión sobre las prácticas es una necesidad de los distintos actores. Concluimos asimismo que la evolución hacia la transdisciplinariedad no puede construirse sin participación de actores y a través de un esquema de pura transmisión. En este sentido, desarrollar la pesquisa desde el método de la (nueva) I-A, que ultrapasa 
la noción de ciencia aplicada y concibe a los actores como sujetos activo-reflexivos en la producción de conocimiento, nos dio la oportunidad de constatar que ésta deviene en un método propicio para gestar procesos transdisciplinares.

\subsubsection{Alternancias Dialógicas: Disciplinariedad/Transdisciplinariedad; Balance Contenidos/Procesos}

Por otra parte, a partir de esta investigación, es clave observar en la práctica, algo que ya habíamos dilucidado en la teoría (Espinosa y Tamariz, 2001): que disciplinariedad y transdisciplinariedad deben aparecer, a la manera dialógica, en los procesos (de formación) universitarios, como cooperantes y complementarias. Por lo que la alternancia entre éstas se presenta como necesaria. Particularmente en el nivel de licenciatura, observamos la importancia de la formación del universitario en una disciplina, pero dejando también espacios para trascenderla viviendo procesos formativos y de colaboración transdisciplinar.

Asimismo, es importante hacer un balance entre contenidos y procesos, que una formación transdisciplinar, debe concebir como elementos de un proceso dialéctico. La formación transdisciplinar está más centrada en los procesos de reflexión, diálogo y producción de saber que en contenido. Así, todo programa de formación debe asumir la equilibración continua, el diálogo dialógico y la alternancia entre disciplinariedad-transdisciplinariedad/contenidos-procesos, según el contexto y los objetivos de formación.

En este orden de ideas, los procesos de institucionalización, a través del registro de validez oficial de los cursos transdisciplinarios ante el ministerio de educación mexicano implicaron también un proceso reorganizador pues hubo que justificar su importancia y pertinencia en la formación universitaria de nivel licenciatura, una vez logrado esto, se allanó en parte el camino para su puesta en práctica. A este respecto, Victoria González (2012, p. 6) quien realizó una estancia de investigación en CEUArkos, señala: "Lo interesante, para mí, de la propuesta de Arkos, es que insertan en la estructura curricular espacios transdisciplinares y los llaman como tales, de manera que los y las estudiantes incorporan en su léxico profesional vocabulario transdisicplinar. Esto a mi entender logra al menos varios impactos. El primero, la hace una propuesta sostenible, es decir que al estar inserta y visible en el curriculum, cuando las personas cambien, la propuesta continuará siendo llevada a la práctica de la formación profesional. Otro es que se orienta en la transformación de las personas y no de las cosas, por lo que no solo hay un impacto curricular, sino también una transformación de la 
forma de vida de las personas. Al cambiar la mirada, cambia la forma de interpretar la realidad y las personas involucradas manifiestan que sus vidas han girado muy positivamente en cuanto a su concientización de los problemas sociales."

\subsubsection{Formación de Formadores: Una Nueva Concepción}

El paradigma emergente permea instituciones como UNESCO, apareciendo la formación de formadores como trascendental, empero, ésta sigue siendo edificada bajo nociones de linealidad, reduccionismo, modelo de ciencia aplicada y escisión entre sujeto y objeto, donde el profesor aparece como transmisor del conocimiento. Aunado a ello, las escuelas aparecen como sometidas al pensamiento económico tendiente a reducir la educación a la adquisición de competencias profesionales que el formador debe transferir (Galvani, 2008). No obstante, con la pesquisa concluimos que es necesario salir del paradigma de la transmisión, reconcebir rol de formador: no sólo orientado a adquirir conocimientos y transmitirlos, sino a construir saber y a trabajar bajo un modelo que combina a la vez que investigación-reflexión-en la acción. Nos referimos también a transformar procesos formativos convirtiendo la propia formación en una práctica transdisciplinar y compleja.

\subsubsection{Triadas Transdisciplinarias para una Formación Universitaria}

Con la pesquisa pudimos ver una relación triádica entre elementos, conceptos y procesos que aunque aparentan ser antagónicos en realidad se nutren mutuamente y apoyan el desarrollo de una formación transdisciplinar. La noción de triada nos ofrece la posibilidad de salir de un pensamiento clásico binario e incorporar una nueva lógica del antagonismo contradictorio. En nuestra experiencia la serie de triadas (abierta e inacabada), que orientó las estrategias para una formación transdisciplinar son: $a$ ) investigaciónßàacciónßàreflexión, b)teoríaßàprácticaßàética, c) aprendizajeßàenseñanzaßàinvestigación, d) cruzamiento de saberesßàdiálogo dialógico e intersubjetivoßà Reflexividad, e) saberes académicos ßàartísticosßà populares, f) racionalidadßàemotividadßàcorporeidad, g) individuoßàsociedadßàespecie/auto-formaciónßàco-formaciónßàeco-formación. Estas triadas representan lo que podemos llamar la pedagogía transdisciplinar del CEUArkos.

2.2.6 Acompañar la reforma del pensamiento hasta una ecologización de los saberes y la formación universitaria

El acercamiento a la complejidad y la transdisciplinariedad produce en la universidad un espacio crítico desde el cual las personas se sienten libres para cuestio- 
nar y manifestar su desapego hacia el modelo socio-económico actual así como para expresar sus deseos por construir un mundo mejor; un esquema social alternativo que trascienda la noción de desarrollo social como económico y permita relaciones más armónicas entre individuoßàsociedadßànaturaleza. Las instituciones interesadas en estas corrientes deben considerar que uno de sus efectos comporta una asunción crítica de la realidad y de una posible postura cuestionante ante dicho modelo. Con esta experiencia vemos que carreras a primera vista ajenas a la educación sobre el medio ambiente (como comunicación, derecho, contaduría, administración, mercadotecnia) son ecologizantes al trabajar bajo una postura transdisciplinar. En otras palabras, observamos que la aproximación transdisciplinar y compleja, que busca organizar y religar las enseñanzas disciplinarias desde problemáticas globales, tiende a ultrapasar el paradigma disciplinario (técnico, reductor, simplificante) y plantea un cuestionamiento crítico en las diferentes disciplinas sobre los desequilibrios medio ambientales y sociales, introduciendo al medio ambiente y lo social como preocupación central de los aprendizajes y conocimientos producidos, apelando a la reintroducción del sujeto cognoscente en todo conocimiento (Morin, 2005) y a una ciencia no amputada de sujeto (Almeida, 2009).

\subsubsection{CEUArkos: Un gran laboratorio de investigaciones transdisciplinares}

Por último diremos, siguiendo a Pineau (en Espinosa, 2014), que aunque cuantitativamente el CEUArkos es una universidad pequeña, su tamaño ciertamente ha facilitado ese movimiento colectivo en espiral de investigación-acción-formación para reducir la fractura entre una finalidad planteada de formar humanos libres y de estructuras disciplinarias atomizantes de otra era. La concepción/construcción/conducción de esta I-A, a la vez individual, grupal e institucional de transformaciones progresivas de prácticas de aprendizaje, de enseñanza, de investigación y de administración, ha generado un gran laboratorio de investigaciones transdisciplinares, no sólo conceptuales sino también metodológicas y socio-existenciales.

Para conocer más detalles sobre el proceso de institucionalización de la transdisciplinariedad y la complejidad en esta universidad, invitamos a la lectura de los textos de Espinosa (2014) y Espinosa y Galvani (2014) citados en las referencias de este artículo. 


\section{Referências}

ALMEIDA, M. C. y KNOBBE, M. M. Ciclos de Metamorfosis. Una experiencia de reforma universitária. Editora Sulina. GRECOM. Brasil. 213 pp. 2003.

ALMEIDA, M. Complejidad y el vuelo incierto de la mariposa. Visión docente conciencia, Año VIII, 47, 5-20. Disponible en: http://www.ceuarkos.com/Vision_docente/ revistas/No.\%2047.pdf. 2009.

BARBIER, R. La Recherche Action. Anthropos. París, Francia. 112 pp. 1996.

BARBIER, R. Investigación-acción. Su historia. Revista Visión Docente Con-Ciencia, (43), 5-13. C.E.U.Arkos. México. 2008.

BOHM, D. On dialogue. Routledge Editorial. Londres. 136pp. 2004.

C.E.U. A. Filosofía Institucional. Centro de Estudios Universitarios Arkos. México. 2001.

D’AMBrosiO, U. Conocimiento y valores humanos. Revista Visión Docente ConCiencia, (35), 6-18. CEUArkos, Puerto Vallarta, Jal. México. 2007.

DESROCHE, H. Les auteurs et les acteurs. La recherche coopérative comme recherche-action. Communautés. Archives de Sciences sociales et de la Coopération et du Développement, (59), 36-94. 1982

ESPINOSA MARTÍNEZ, A. C. y TAMARIZ, C Un modelo transdisciplinario de educación para la Universidad. Tesis de maestría sin publicar. Universidad de Valle de México. Santiago de Querétaro. México. 506pp. 2001.

ESPINOSA MARTÍNEZ, A. C. II Congreso Mundial de Transdisciplinariedad. Revista Visión Docente Con-Ciencia, (27), 12-17. C.E.U.Arkos. México. 2005.

ESPINOSA MARTÍNEZ, A. C. Estrategias metodológicas para operacionalizar la práctica educativa transdisciplinaria, en conjunto con los actores universitarios, en las licenciaturas del Centro de Estudios Universitarios Arkos de Puerto Vallarta, Jalisco, México. 
Tesis Doctoral. Universidad Estatal a Distancia de Costa Rica. San José, Costa Rica. 913pp. 2010.

ESPINOSA MARTÍNEZ, A. C. y GALVANI, P. “Transdisciplinariedad y formación universitaria: Teorías y prácticas emergentes” Centro de Estudios Universitarios Arkos. México. 2014.

ESPINOSA MARTÍNEZ, A. C. "Abrir los saberes a la complejidad de la vida: Nuevas prácticas universitarias en la universidad." Centro de Estudios Universitarios Arkos. México. 2014.

GALVANI, P. La reflexividad sobre la experiencia: Una perspectiva transdisciplinar sobre la autoformación. 1 ${ }^{\text {a }}$ Parte. Revista Visión Docente Con-Ciencia, (36), 5-11. C.E.U.Arkos. México. 2007.

GALVANI, P. Metodology. En: Fourth World University Research Group. The merging of Knowledge. People in poverty and academics thinking together. University Press of America. United States. p. 9-30. 2007b.

GONZÁLEZ, V. La transdisciplinariedad: una pasantía en CEUArkos, Puerto Vallarta, México. Ponencia de participación en el IV Forum internacional innovación y creatividad. Barcelona. 2012

JANTSCH, E. Hacia la interdisciplinariedad y la transdisciplinariedad en la enseñanza y la innovación. En A. Leo, G. Berger, A. Briggs y G. Michaud (Aut.), Interdisciplinariedad: Problemas de la enseñanza y de la investigación en las. 1979.

MATURANA, H. y VARELA, F. El árbol del conocimiento. Las bases biológicas del entendimiento humano. Lumen. Argentina. 172 pp. 2003.

MATURANA, H. y VARELA, F. De máquinas y seres vivos: Autopoiesis, la organización de lo vivo. Editorial Universitaria. Chile. 137 pp. 1998.

MORAES, M. C. Ecologia dos saberes. Complexidade, transdisciplinaridade e educacâo. Novos fundamentos para iluminar Novas práticas educacionais. Editorial Willis Harman House y Porolíbera. Brasil. 301 pp. 2008. 
MORIN, E. Los sietes saberes necesarios para la educación del futuro. UNESCO. México. 67 pp. 2001.

MORIN, E. La cabeza bien puesta. Repensar la reforma, reformar el pensamiento. Nueva Visión. Argentina. 143 pp. 2002.

MORIN, E. Introducción al pensamiento complejo. Editorial Gedisa. España. 167 pp. 2005.

MORIN, E. El método 1: La naturaleza de la naturaleza. Editorial Cátedra. Colección Teorema. México. 272 pp. 2006.

MORIN, E. El método 2: La vida de la vida. Editorial Cátedra. Colección Teorema. México. 544 pp. 2006 a.

MORIN, E. El método 3: El conocimiento del conocimiento. Antropología del conocimiento. Editorial Cátedra. Colección Teorema. México. 264 pp. 2006 b.

MORIN, E. El método 4: Las ideas: su habitat, su vida, sus costumbres, su organización. Editorial Cátedra. Colección Teorema. México. 272 pp. 2006c.

MORIN, E. El método 5: La humanidad de la humanidad. La identidad humana. Editorial Cátedra. Colección Teorema. México. 2006d.

MORIN, E. El método 6: Ética. Editorial Cátedra. Colección Teorema. México. 2006e.

NICOLESCU, B. La transdisciplinariedad, una nueva visión del mundo. Manifesto. Centro Internacional para la Investigación Transdisciplinaria (CIRET). Ediciones Du Rocher. Francia. 125 pp. Disponible en: http://perso.club-ginternet.fr/nicol/ciret/. 1998.

NICOLESCU, B. Transdisciplinariedad: presente, pasado y futuro. $1^{\text {a }}$ parte. Revista Visión Docente Con-Ciencia, (31), 15-31. C.E.U.Arkos. México. 2006.

PAYETTE, A. et CHAMPAGNE, C. Le groupe de co-développement professionnel, SteFoy: Les Presses de l'Université du Québec. 1997. 
PINEAU, G. \& MORIN, E.: itinerario y obras de un autor transdisciplinario. Revista Visión Docente Con-Ciencia, (34), 5-14. C.E.U.Arkos, México. 2007.

PINEAU, G. Knowledge: Freeing knowledge! Life, school and action. En: Fourth World University Research Group (Ed.) The merging of knowledge. People in poverty and academics thinking together. (pp. 215-306). E.U.A: University press of America. 2007b.

PIAGET, J. Biología y conocimiento. Ensayo sobre las relaciones entre las regulaciones orgánicas y los procesos cognoscitivos. Editorial Siglo XXI. México. 338 pp. 1980.

REYNAGA, R. Una aproximación axiológica de transdisciplina y pensamiento complejo. Multiversidad Mundo Real. Obtenido el 4 de Agosto de 2007, de: http://wwwmultiversidadreal.org/. 2006.

SCHÖN, D. The reflective practitioner. How professionals think in action. Ashgate. England. 374 pp. 2006.

THOMPSON KLEIN, J. The Transdisciplinary Moment(um). Revista: Integral Review. Vol. 9. N². Estados Unidos de Norte América. P. 189-199. 2013.

UNESCO Los Cuatro Pilares de la Educación en: Informe a la UNESCO de la Comisión Internacional sobre la Educación para el siglo XXI. Editorial Magisterio del Río de la Plata. Buenos Aires. 1997.

Recebido em: 04 abril 2016

Aceito em: 15 abril 2016 